\title{
Optical properties of doping electrochromic M0.125W0.87503 (M=Mo, Nb, Ta, Ti, V): A first- principles study
}

Yuanyuan Cui ( $\nabla$ cui-yy@shu.edu.cn )

Shanghai University

Qinfan Wang

Shanghai University School of Materials Science and Engineering

Bin Liu

Shanghai University School of Materials Science and Engineering

Yanfeng Gao

Shanghai University School of Materials Science and Engineering

\section{Research Article}

Keywords: Tungsten trioxide, Doping, Electrochromism, First-principles calculation, Optical properties

Posted Date: May 3rd, 2020

DOI: https://doi.org/10.21203/rs.3.rs-25346/v1

License: (c) (i) This work is licensed under a Creative Commons Attribution 4.0 International License. Read Full License

Version of Record: A version of this preprint was published at Materials Today Communications on December 1st, 2020. See the published version at https://doi.org/10.1016/j.mtcomm.2020.101611. 


\title{
Optical properties of doping electrochromic $M_{0.125} \mathrm{~W}_{0.875} \mathrm{O}_{3}(M=M o, \mathrm{Nb}, \mathrm{Ta}, \mathrm{Ti}, \mathrm{V}): \mathrm{A}$ first-principles study
}

\author{
Yuanyuan Cui, Qinfan Wang, Bin Liu, Yanfeng Gao* \\ School of Materials Science and Engineering, Shanghai University, Shanghai 200444, China
}

Abstract: Tungsten trioxide $\left(\mathrm{WO}_{3}\right)$ is a representative electrochromic material that can change their optical properties under the action of a voltage pulse and has attracted great interest in the applications of energy efficient windows. Models of various $\mathrm{W}_{0.125} M_{0.875} \mathrm{O}_{3}$ and $\mathrm{Li}_{x} M_{0.125} \mathrm{~W}_{0.875} \mathrm{O}_{3}(M=\mathrm{Mo}, \mathrm{Nb}, \mathrm{Ta}, \mathrm{Ti}, \mathrm{V})$ were built to simulate the bleached and colored state of $\mathrm{WO}_{3}$ materials by first-principles calculations, respectively. The calculations show that doping systems of $\mathrm{Li}_{x} M_{0.125} \mathrm{~W}_{0.875} \mathrm{O}_{3}(M=\mathrm{Nb}$, Ta, V) lead to an enhancement of the modulation efficiency in invisible light and a decrease in the modulation efficiency in near infrared region (NIR). Ti doping boosts an excellent high efficiency of NIR modulation, while no modulation was observed in the visible light region. Mo doping remarkably promotes the coloration efficiency in both NIR and visible regions. The specific characteristics of doped $\mathrm{WO}_{3}$ systems deserve more exploration of their application in green house or thermal modulation smart window.

Keywords: Tungsten trioxide; Doping; Electrochromism; First-principles calculation; Optical properties

*E-mail address: yfgao@shu.edu.cn (Yanfeng Gao) 


\section{Introduction}

Firstly reported by S. K. Deb in 1969, $\mathrm{WO}_{3}$ has attracted a huge amount of interests due to its electrochromic property [1]. This phenomenon characterizes the $\mathrm{WO}_{3}$ material as a kind of smart electrochromic material to be utilized on smart windows where the color and optical properties may change according to individual needs. With the change of temperature, $\mathrm{WO}_{3}$ presents different polymorphisms, such as $\varepsilon-\mathrm{WO}_{3}, \delta$ $\mathrm{WO}_{3}, \gamma-\mathrm{WO}_{3}, \beta-\mathrm{WO}_{3}$, with the crystalline structures of monoclinic, triclinic, monoclinic and orthorhombic, respectively [2]. All polymorphisms involve the tilting of W-O octahedrons. The more $\mathrm{W}-\mathrm{O}$ octahedrons tilt, the less symmetry $\mathrm{WO}_{3}$ possesses. Moreover, there exist other different structures in $\mathrm{WO}_{3}$. For instance, $\mathrm{h}-\mathrm{WO}_{3}$ is another well-known polymorphism of $\mathrm{WO}_{3}$ with hexagon tunnels, which is synthesized by the solvothermal method with a water-controlled release process [3] and a- $\mathrm{WO}_{3}$ is a structure of glass state with disordered $\mathrm{WO}_{6}$ octahedral in it. In general, $\mathrm{WO}_{3}$ exhibits a monoclinic crystalline structure in the room temperature. The structure of pure $\gamma-\mathrm{WO}_{3}$ can be described as distorting perovskite structure $\left(\mathrm{ABO}_{3}\right)$ without atom in $\mathrm{A}$ site $[4,5]$. In fact, crystalized $\gamma-\mathrm{WO}_{3}$ boasts an excellent coloration efficiency and stability [6].

The electrochromic property of $\mathrm{WO}_{3}$ can be interpreted by different models. Faughnan's model, which is also called the intercalation/deintercalation model, is a widely accepted one $[7,8]$. The alkali metal ions enter the $\mathrm{WO}_{3}$ layer (light yellow) and locate at $\mathrm{WO}_{6}$ octahedral sites (Fig. $1(\mathrm{a}, \mathrm{b})$ ), which may result in the formation of tungsten bronze $\mathrm{Li}_{x} \mathrm{WO}_{3}$ (blue) [2, 4]. This process is called intercalation and deintercalation process of $\mathrm{Li}^{+}$, which can be realized through a combined device with electrolyte, conducting glass, $\mathrm{WO}_{3}$ layer and a counter electrode. Once the $\mathrm{WO}_{3}$ is placed into the sandwich appliance (Fig. 1 (c)) [9], the coloration happens in the $\mathrm{WO}_{3}$ material when there exists a positive voltage on both sides of the $\mathrm{WO}_{3}$ layer while it fades if the voltage is negative [10]. The coloration happens within only a few seconds after the voltage is applied. Besides, the color of $\mathrm{WO}_{3}$ layer will also vary according to different voltages [6]. The $\mathrm{WO}_{3}$ layer is nearly transparent before the injection of ions 
and yet it becomes dark blue and opaque after the injection of ions (with a range of concentration), which indicates that the optical properties of the $\mathrm{WO}_{3}$ layer in the visible light can be adjusted [11]. According to the work by L. Berggren [12], changes of optical properties in infrared light also take place along with the coloration and the fading. The absorption coefficient increased from 0 to nearly $5 \times 10^{5} \mathrm{~cm}^{-1}$ during the coloration period hence results in a thermal regulation [13].

In experiments, alkali ions, such as $\mathrm{H}^{+}, \mathrm{Li}^{+}, \mathrm{Na}^{+}$are always employed as the intercalated ions [1]. However, $\mathrm{H}^{+}$ions in $\mathrm{WO}_{3}$ system are unstable and can be easily captured by $\mathrm{W}^{6+}$ to form $\mathrm{C}-\mathrm{H}_{2} \mathrm{O}$ and $\mathrm{WO}_{3} \cdot x \mathrm{H}_{2} \mathrm{O}$, which may affect the reversibility of devices [14] and the diffusion is more efficient for ions with smaller ion radii [15], hence in this paper, $\mathrm{Li}^{+}$is selected. It is inspected that the color of $\mathrm{WO}_{3}$ material is related to the number of alkali ions. $\mathrm{WO}_{3}$ will appear to be dark blue if the concentration of injected ions is lower than 0.5. In fact, concentration of injected ions is often lower than 0.3 in experiments [16].
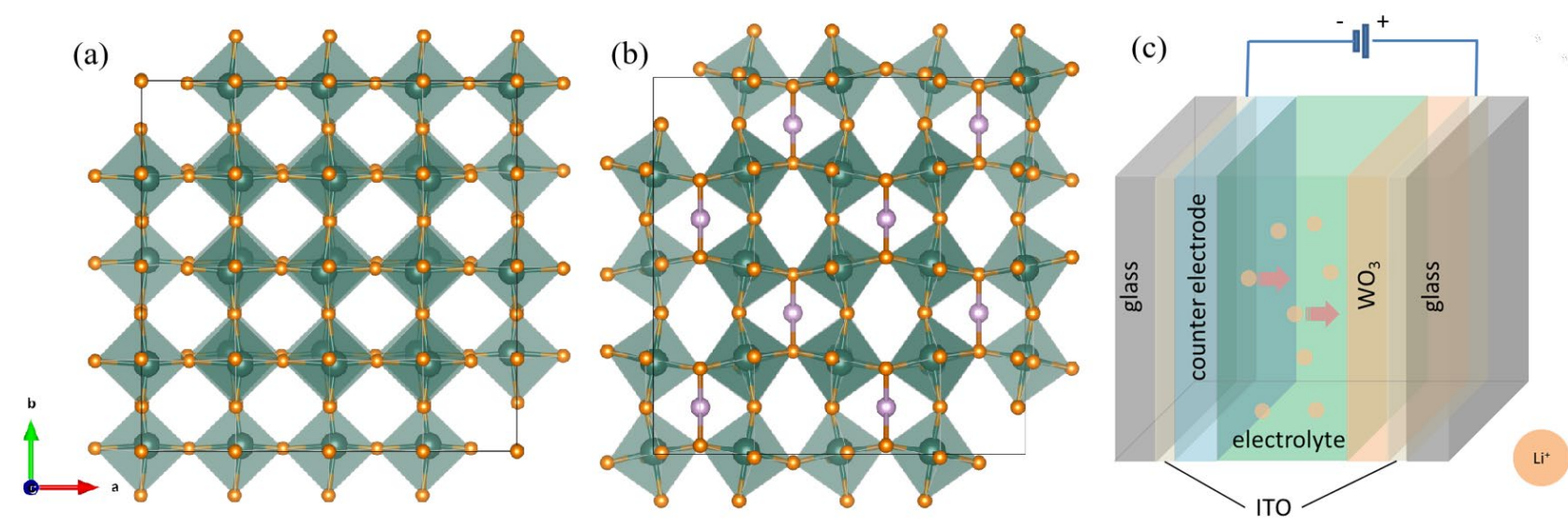

Fig. 1. The structure of (a) pure $\gamma-\mathrm{WO}_{3}$; (b) $\mathrm{Li}_{x} \mathrm{WO}_{3}$; green octahedrons: $\mathrm{WO}_{6}$; orange atoms: $\mathrm{O}$ atoms; pink atoms: Li atoms; green atoms: W (c) the sandwich appliance of electrochromic materials octahedrons.

There are many problems remaining to be solved in $\mathrm{WO}_{3}$ material, such as long response time, low cycle index, modulation efficiency and optical properties, etc. [9] Several methods have been taken to deal with these problems such as elemental doping [17], construction of microstructure [18], the designation of interfaces [19], etc. For instance, through construction of microstructure, Jiao et al. [20]synthesized the 
nanostructured $\mathrm{WO}_{3}$ film with an excellent reversibility to more than 1000 circles. Wang et al. [13] discovered that the structure distortion may enhance the absorption from $10^{1}$ to $10^{4} \mathrm{~cm}^{-1}$ in light energy period of 0 to $7 \mathrm{eV}$. Considering the doping, Gesheva et al. [21] evaluated the optical band gap energies of Mo doped $\mathrm{WO}_{3}$ and the optical band gap ranged from $2.9 \mathrm{eV}$ to $3.1 \mathrm{eV}$, which changed the optical properties of $\mathrm{WO}_{3}$. Park [22] observed that the $\mathrm{Au}$ doped $\mathrm{WO}_{3}$ had a reversed optical modulation to the pure $\mathrm{WO}_{3}$. Aliev and Shin [23] successfully modified the $\mathrm{T}_{90}$ (time taken for the transmittance change by $90 \%$ of the total difference between the fully bleached and fully colored states) of the $\mathrm{WO}_{3}$ layer $96 \mathrm{~s}$ to $68 \mathrm{~s}$ by $\mathrm{TiO}_{2}$ solid solution. Yoon-Chae Nah et al. [24] synthesized $\mathrm{TiO}_{2}$ and $\mathrm{WO}_{3}$ nanotubes interfaces to make the system exhibit a good cycling index.

As it is summarized by Niklasson G. A. and C.G. Granqvist [6], the modulation of visible light and infrared light always happens simultaneously. Accordingly, the modulation of light and heat of sunlight in $\mathrm{WO}_{3}$ occur together. As a result, the exchange of light and heat is coupled, which limits the usage of $\mathrm{WO}_{3}$ glass for situations that call for single modulation of light or heat, which remains an aspect to be improved. $\mathrm{WO}_{3}$ is a kind of cathode electrochromic material [6] hence in the present study, we attempt to modulate the infrared light and visible light of the $\mathrm{WO}_{3}$ separately, via doping, such as Mo, Nb, Ta, Ti and V whose oxides have cathode electrochromic property, with the purpose of the modulating the visible light and infrared light separately and exploring more utilization of $\mathrm{WO}_{3}$. For example, to make $\mathrm{WO}_{3}$ material be transparent in visible light and infrared light in bleached state while has a high reflectivity in visible state and high transmissivity in infrared state. Therefore, dopant of a series of transition metals may result in the change in the band structure and the alteration of the spectrum, which can be implemented to modulate the electrochromic property of $\mathrm{WO}_{3}$.

The content of this paper is arranged as following: Computation details are profiled in Section 2. The basic structure of $\mathrm{WO}_{3}$ material is described in Section 3.1. Section 3.2 includes the concentration of $\mathrm{Li}^{+}$ions and Section 3.3 contains the 
calculation of electronic structures of doped $\mathrm{WO}_{3}$. Section 3.4 contains the summary of optical properties of $M_{x} \mathrm{WO}_{3}$. At the end of this paper, the results are concluded in Section 4.

\section{Computation details}

All calculations mentioned in this paper are based on the density function theory and performed with the generalized gradient approximation (GGA) and pseudopotential methods are projector augmented wave (PAW) [25] and Perdew-BurkeErnzerh (PBE) [26] in the Vienna $A b$-initio Simulation Package (VASP) [27]. $\mathrm{Li}^{+}$ concentration test calculations have been carried out in $2 \times 1 \times 1$ superlattices. $4 \times 2 \times 1$ superlattices of pure $\mathrm{WO}_{3}, \quad \mathrm{Mo}_{0.125} \mathrm{~W}_{0.875} \mathrm{O}_{3}, \quad \mathrm{Nb}_{0.125} \mathrm{~W}_{0.875} \mathrm{O}_{3}, \quad \mathrm{Ta}_{0.125} \mathrm{~W}_{0.875} \mathrm{O}_{3}$, $\mathrm{Ti}_{0.125} \mathrm{~W}_{0.875} \mathrm{O}_{3}$ and $\mathrm{V}_{0.125} \mathrm{~W}_{0.875} \mathrm{O}_{3}$, are constructed by primitive unit cells. All calculations were conducted without spin-polarization. Basic calculations were carried out with $2 \times 2 \times 4 k$-point meshes. The cut-off energy of plane wave basis for bleached and colored $\mathrm{WO}_{3}$ materials is set as $520 \mathrm{eV}$ and $648 \mathrm{eV}$, respectively. All these lattice constants are optimized until the total energy converged to $1 \times 10^{-10} \mathrm{eV}$.

Optical properties of materials can be described by the reflectivity and the absorption, which are related to the dielectric function $[28,29,30]$ :

$$
\varepsilon(\omega)=\varepsilon_{1}(\omega)+\varepsilon_{2}(\omega)
$$

In this equation $\varepsilon_{2}(\omega)$ describes the unoccupied (conduction band) and occupied (valence band) states, respectively. What's more, in this paper the direction of $\varepsilon(\omega)$ is opted on the $x$ axis since the crystallized $\mathrm{WO}_{3}$ film possesses a $\left(\begin{array}{lll}2 & 0 & 0\end{array}\right)$ orientation on the surface [31].With $\varepsilon_{2}(\omega)$ and $\varepsilon_{1}(\omega)$, reflection $R(\omega)$ and absorption $\alpha(\omega)$ can be acquired through equations:

$$
\begin{aligned}
& \alpha(\omega)=\sqrt{2} \omega\left[\sqrt{\varepsilon_{1}^{2}(\omega)+\varepsilon_{2}^{2}(\omega)}-\varepsilon_{1}(\omega)\right]^{1 / 2} \\
& R(\omega)=\left|\frac{\sqrt{\varepsilon_{1}(\omega)+\varepsilon_{2}(\omega)}-1}{\sqrt{\varepsilon_{1}(\omega)+\varepsilon_{2}(\omega)}+1}\right|^{2}
\end{aligned}
$$

The coloration efficiency is also employed to evaluate the coloration of $\mathrm{WO}_{3}$, 
which can be summarized as:

$$
\eta=\left|\log \frac{T_{C}}{T_{B}}\right| / Q
$$

In Equation $4, T_{\mathrm{C}}$ is the transmissivity in colored state and $T_{\mathrm{B}}$ is the one in the bleached state. Here $Q$ is a constant of electric charge. Equation 4 indicates that if $T_{\mathrm{C}}<T_{\mathrm{B}}$, the higher $T_{\mathrm{C}}$ is, the lower $\eta$ will be, vice versa.

\section{Results and discussion}

\subsection{Basic atomic structure of the bulk $\mathrm{WO}_{3}$}

All $\mathrm{WO}_{3}$ models are established with the lattice structure of $\gamma-\mathrm{WO} 3$, which is also called room temperature phase (RT). Table 1 lists the lattice parameters and lattice volumes derived from different methods. Compared with experimental data, both results of lattice parameters from LDA and GGA have an error under 4\% while the lattice parameters calculated from the LDA method in this work is more comparable with the experimental data and the GGA method may overestimate the lattice constants in bulk materials. Nevertheless, as it is shown in pictures of density of function (see Fig. S1 in supplementary materials), the band gap results obtained from LDA and GGA are 1.132 $\mathrm{eV}$ and $1.287 \mathrm{eV}$, respectively, compared with the experimental result $2.62 \mathrm{eV}$ [35]. The band gap of HSE06 methods is $2.80 \mathrm{eV}$. Although results in this paper conform to others' calculated results, all methods except HSE06 cause an underestimation of band gap, which is the feature of LDA/GGA. However, the HSE06 methods in following optical calculations will be very time-consuming. Comparing to all other methods, the GGA method works better than LDA when it refers to the band gap and it works more efficiently than HSE06 methods. As the research concerns much about optical properties and it tend to compare the optical properties among several systems, therefore, the GGA method is employed in the following calculations. 
Table 1 Lattice parameters and lattice volumes for $\gamma-\mathrm{WO}_{3}$ derived from LDA, GGA methods and experiment.

\begin{tabular}{ccccccccc}
\hline Methods & $a(\AA)$ & $b(\AA)$ & $c(\AA)$ & $\alpha\left(^{\circ}\right)$ & $\beta\left(^{\circ}\right)$ & $\gamma\left({ }^{\circ}\right)$ & $V\left(\AA^{3}\right)$ & Ref. \\
\hline LDA & 3.820 & 7.500 & 7.290 & 90 & 90.8 & 90 & 208.838 & Exp.[32] \\
GGA & 3.806 & 7.524 & 7.371 & 90 & 90.3 & 90 & 211.075 & this work \\
GGA & 3.840 & 7.700 & 7.760 & 90 & 90.2 & 90 & & Cal.[33] \\
PBE \& PW91 & 3.770 & 7.700 & 7.870 & 90 & 90.1 & 90 & & Cal.[34] \\
HSE06 & 3.695 & 7.390 & 7.640 & 90 & 90.3 & 90 & - & Cal.[34] \\
\hline Error of LDA & $-0.3 \%$ & $0.31 \%$ & $1.109 \%$ & 0 & $-0.58 \%$ & 0 & $1.07 \%$ & - \\
\hline Error of GGA & $2.95 \%$ & $3.25 \%$ & $3.48 \%$ & 0 & $-0.63 \%$ & 0 & $10.03 \%$ & - \\
\hline
\end{tabular}

\subsection{Concentration of alkali ions in colored state of $\mathrm{WO}_{3}$}

In colored state of $\mathrm{WO}_{3}$, the concentration of alkali ions may greatly affect the optical properties and electron structure of $\mathrm{WO}_{3}$ so that several models are built with different number of $\mathrm{Li}^{+}$to determine the concentration of $\mathrm{Li}^{+}$with a better coloration efficiency.

\subsubsection{Optical properties of $\mathrm{Li}_{x} \mathrm{WO}_{3}$}

Fig. 2 suggests the calculated absorption and reflectivity spectrum of colored $\mathrm{Li}_{x} \mathrm{WO}_{3},(x$ denotes the concentration of alkali ions). In general, the relationship among the absorption $\alpha$, reflectivity $R$ and transmissivity $T$ can be summarized as $\alpha+R+T=1$, which conforms to the normalization. In the NIR range, a promotion of the reflectivity and the absorption appear in $\mathrm{WO}_{3}$ after $\mathrm{Li}^{+}$ions are injected. When the concentration of $\mathrm{Li}$ is 0.125 , the reflectivity of NIR in the long-wave infrared region $(0.104-0.155 \mathrm{eV})$ 
increases by $27.78 \%$ (integral area) while in the medium-wave infrared region $(0.248$ $0.414 \mathrm{eV}$ ) there exists no apparent enhancement whereas if the concentration is 0.25 and 0.5 , the reflectivity of $\mathrm{WO}_{3}$ in two infrared atmospheric windows drastically enhances. The reflectivity of $\mathrm{Li}_{0.25} \mathrm{WO}_{3}$ and $\mathrm{Li}_{0.5} \mathrm{WO}_{3}$ climb to 0.55 and 0.59 in the long-wave infrared region respectively. What's more, in the medium-wave infrared region, the reflectivity of $\mathrm{Li}_{0.25} \mathrm{WO}_{3}$ reaches 0.55 and the one of $\mathrm{Li}_{0.5} \mathrm{WO}_{3}$ reaches 0.66. Nevertheless, the reflectivity of $\mathrm{LiWO}_{3}$ descends to 0.37 and 0.35 in two infrared regions. The transmissivity of infrared light in $\mathrm{Li}_{x} \mathrm{WO}_{3}$ can be ranked as $\mathrm{Li}_{0.5} \mathrm{WO}_{3}<$ $\mathrm{Li}_{0.25} \mathrm{WO}_{3}<\mathrm{Li}_{1.0} \mathrm{WO}_{3}<\mathrm{Li}_{0.125} \mathrm{WO}_{3}$. Thus, with respect to reflectivity in NIR region, the $\mathrm{Li}_{0.25} \mathrm{WO}_{3}$ and $\mathrm{Li}_{0.5} \mathrm{WO}_{3}$ boast a good performance and an effective modulation.

In visible light region (1.59-3.27 eV), as it is illustrated (Fig. 2 (a)), the absorption curve of the pure $\mathrm{WO}_{3}$ soars at nearly $2.5 \mathrm{eV}(496.9 \mathrm{~nm})$ which suggests an absorption of blue light (2.38-2.64 eV) and an appearance of yellow color $(2.08-2.14 \mathrm{eV})$ hence it is in accordance of experimental results. Moreover, the $\mathrm{Li}_{0.5} \mathrm{WO}_{3}$ exhibits a maximum absorption wavelength at near $3.27 \mathrm{eV}(380 \mathrm{~nm})$, which indicates a green color of $\mathrm{Li}_{0.5} \mathrm{WO}_{3}$. As a result, it may decrease the coloration efficiency $\eta$ in Equation 4. One can discover (Fig. 2 (a) and (b)) that the $\mathrm{Li}_{0.25} \mathrm{WO}_{3}$ boosts the absorption and reflection within the almost the whole range of visible light which leads up to a decline of the transmissivity in visible light range and an excellent coloration efficiency $\eta$ [36], which can be attributed to intrinsic and free carrier absorption who is responsible for visible light absorption and infrared light absorption, respectively.

(a)

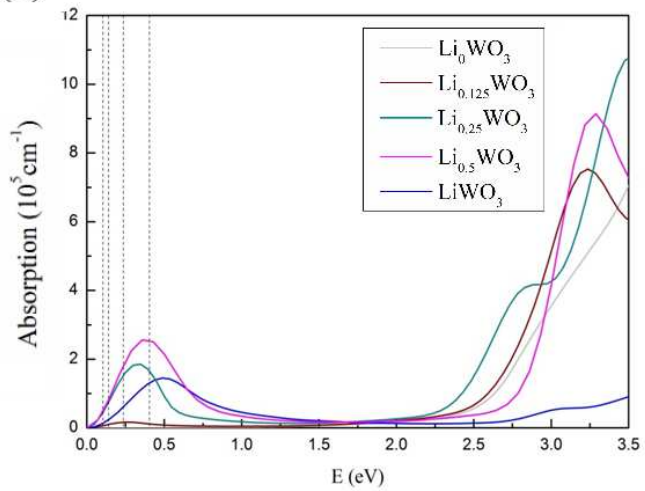

(b)

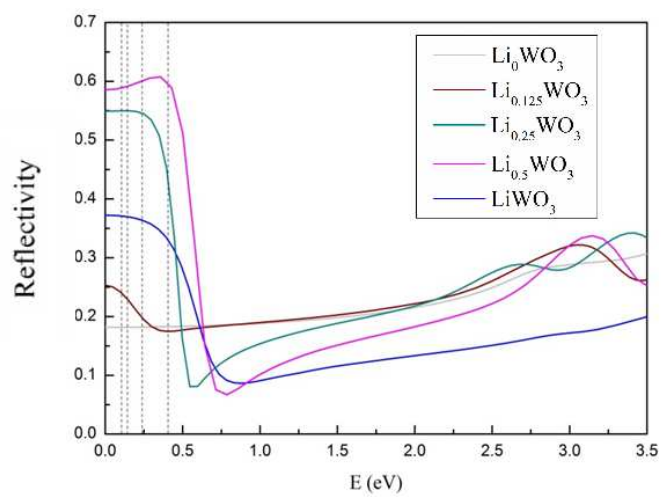


Fig. 2. Optical properties of colored $\mathrm{WO}_{3}$ in NIR and visible light range (a) absorption (b) reflectivity; dash lines highlight two infrared atmospheric windows.

\subsubsection{Band structures of $\mathrm{Li}_{x} \mathrm{WO}_{3}$}

Fig. 3 demonstrates band structures of various $\mathrm{Li}_{x} \mathrm{WO}_{3}$ systems $(x=0,0.125,0.25$, $0.5,1)$. When the concentration is 0 (pure $\mathrm{WO}_{3}$ ) (Fig. 3 (a)), as the Fermi level: $E_{\text {Fermi }}$ is in the middle of band gap, the electron structure is in accord with Boltzmann distribution which indicates that $\mathrm{WO}_{3}$ is a conventional semiconductor material with a band gap of $1.154 \mathrm{eV}$.

Once alkali metal $\mathrm{Li}^{+}$ions are introduced into $\mathrm{WO}_{3}$, energy levels of $\mathrm{Li}^{+}$appear on the conduction band minimum CBM. In $\mathrm{Li}_{0.125} \mathrm{WO}_{3}$ system and $\mathrm{Li}_{0.25} \mathrm{WO}_{3}$ system (Fig. 3 (b) and Fig. 3 (c)), band gaps are narrowed to $0.511 \mathrm{eV}$ and $0.625 \mathrm{eV}$ with $E_{\text {Fermi }}$ raise up into $\mathrm{CB}$. Three levels are noted by red arrows and electrons bounded on these levels give rise to the absorption of photon. These levels moving under $E_{\text {Fermi }}$ because of the bonding between $\mathrm{O} 2 \mathrm{p}$ electrons and $\mathrm{W} 5 \mathrm{~d}$ electrons. Besides the intrinsic absorption, impurity absorption in NIR region can be attributed to these levels if the lowest photon energy $\hbar \omega_{0}$ is higher than $E_{I}$ ( $E_{\mathrm{I}}$ : ionization energy). Impurity absorption peak in NIR region of $\mathrm{Li}_{0.125} \mathrm{WO}_{3}$ system is smaller than the one of $\mathrm{Li}_{0.25} \mathrm{WO}_{3}$, which indicates that $E_{\mathrm{I}}$ in $\mathrm{Li}_{0.25} \mathrm{WO}_{3}$ system is higher. In $\mathrm{Li}_{0.25} \mathrm{WO}_{3}$, as the system is a direct-gap semiconductor, the small peak at $2.75 \mathrm{eV}$ may be caused by exciton absorption. However, with the increase of the concentration $x$, the band structures tend to change. When the concentration is 0.5 and 1 (Fig. 3 (d) and (e)), $\mathrm{Li}_{0.5} \mathrm{WO}_{3}$ and $\mathrm{LiWO}_{3}$ have similar band structures. Especially in $\mathrm{LiWO}_{3}$, the system has a structure as $\mathrm{CaTiO}_{3}$ with high symmetry thus the band structure is also symmetrical. $\mathrm{W}$ atoms in $\mathrm{Li}_{0.5} \mathrm{WO}_{3}$ and $\mathrm{LiWO}_{3}$ are prone to be $\mathrm{W}^{5+}$. As a transition metal, bands of d electrons are not totally filled so that it can acquire more electrons. As the energy levels of $d$ electrons are lower than the ones of s electrons so that in the crystal energy levels shift down quite much under $E_{\text {Fermi. }}$. 

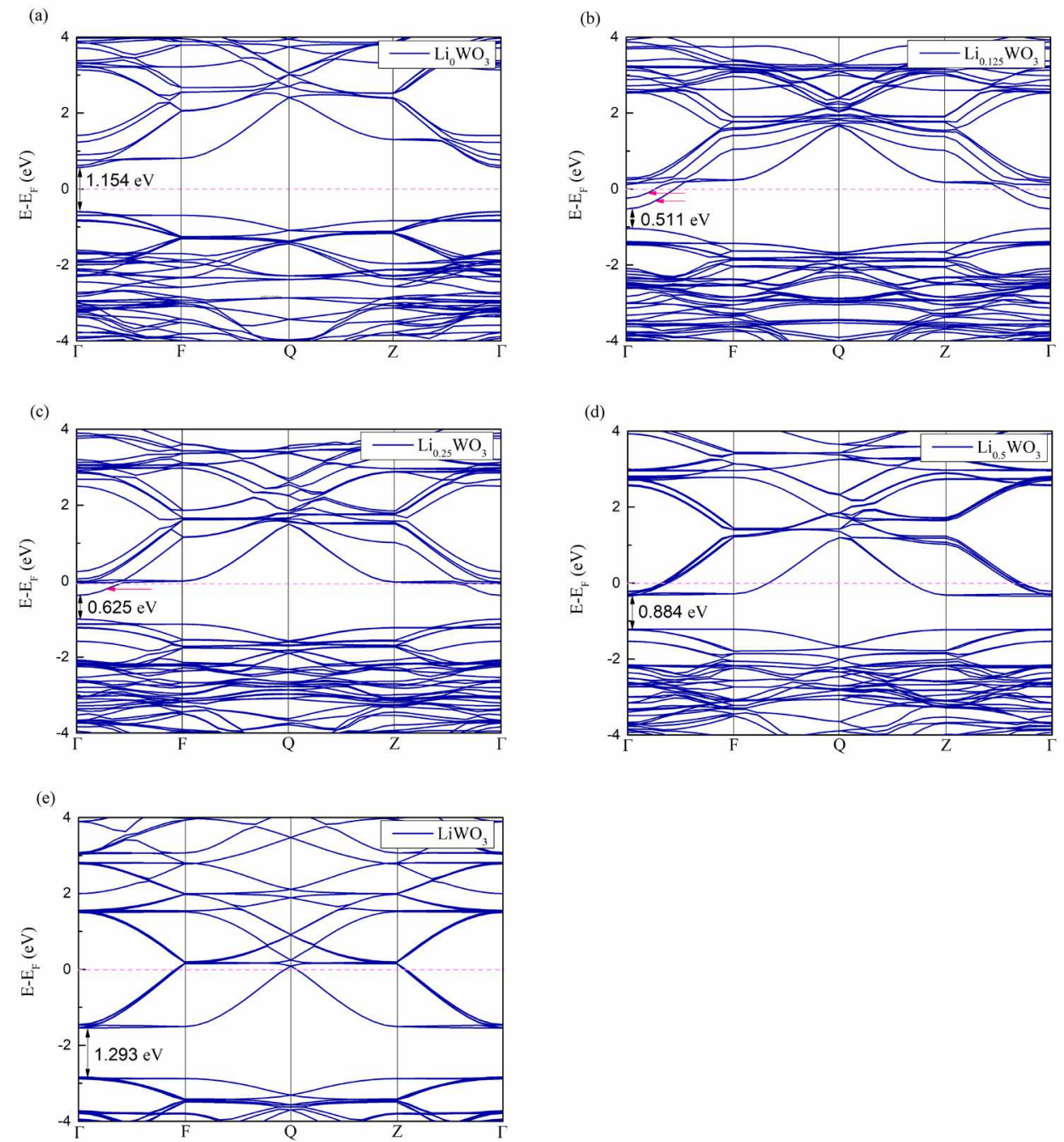

Fig. 3. Band structures of $\mathrm{Li}_{x} \mathrm{WO}_{3}$ systems $(x=0,0.125,0.25,0.5,1)$.

Moreover, a series of $\mathrm{W}_{7} M_{1} \mathrm{O}_{24}(M=\mathrm{Mo}, \mathrm{Nb}, \mathrm{Ta}, \mathrm{Ti}, \mathrm{V})$ crystals were built and 2 $\mathrm{Li}^{+}$ions are manually set in $2 \mathrm{~A}$ sites as it is mentioned in the introduction. According to the lowest energy principle, with each kind of $M$ element, the position of $2 \mathrm{Li}^{+}$is different in individual system.

\subsection{Electronic structures of $M_{x} \mathrm{WO}_{3}$}

The band structures of $\gamma-\mathrm{WO}_{3}$ and $M_{0.125} \mathrm{~W}_{0.875} \mathrm{O}_{3}(M=\mathrm{Mo}, \mathrm{Nb}, \mathrm{Ta}, \mathrm{Ti}, \mathrm{V})$ in bleached states are demonstrated in Fig. 4. As Mo atom $\left(4 d^{5} 5 s\right)$ has the similar electron structure to $\mathrm{W}$ atom $\left(\mathrm{f}^{14} 5 \mathrm{~d}^{4} 6 \mathrm{~s}^{2}\right)$ with six outside electrons, both $\mathrm{Mo}_{0.125} \mathrm{~W}_{0.875} \mathrm{O}_{3}$ and pure $\mathrm{WO}_{3}$ accord with Boltzmann distribution with the $E_{\text {Fermi }}$ in the middle of band gap 
as it is demonstrated (Fig. 4 (a) and Fig. 4 (b)). Once Ta, Nb, V, Ti atoms are introduced into $\mathrm{WO}_{3}$, (Fig. 4 (c), (d), (e) and (f)) in bleached states, $E_{\text {Fermi }}$ in all these four models are shifted down due to the different valences among $\mathrm{W}$ and $\mathrm{Nb} / \mathrm{Ta} / \mathrm{V}$. $\mathrm{W}$ is hexavalent and $\mathrm{Nb}, \mathrm{Ta}, \mathrm{V}$ atoms are pentavalent and $\mathrm{Ti}$ atom is tetravalent. Once lower-valent atoms were introduced into $\mathrm{WO}_{3}$, the electron hole formed in lattices. As it is shown (Fig. 4 (c), (d), (e) and (f)) that several acceptor energy levels $\left(E_{\mathrm{A}}\right)$ appear on the valence energy levels $\left(E_{\mathrm{v}}\right)$ of $\mathrm{WO}_{3}$ and these systems perform as p-type semiconductors. $E_{\mathrm{Fermi}}$ in $\mathrm{Nb}, \mathrm{Ta}, \mathrm{V}$ doping systems appear near $E_{\mathrm{V}}$ while Ti doping system has a lower position of $E_{\mathrm{Fermi}}$ right in the valence band $\left(E_{\mathrm{v}}-E_{\mathrm{Fermi}}=0.1965 \mathrm{eV}\right)$, which indicates that with more impurity levels, Ti doping system is not only a p-type semiconductor but also a degenerate semiconductor. 

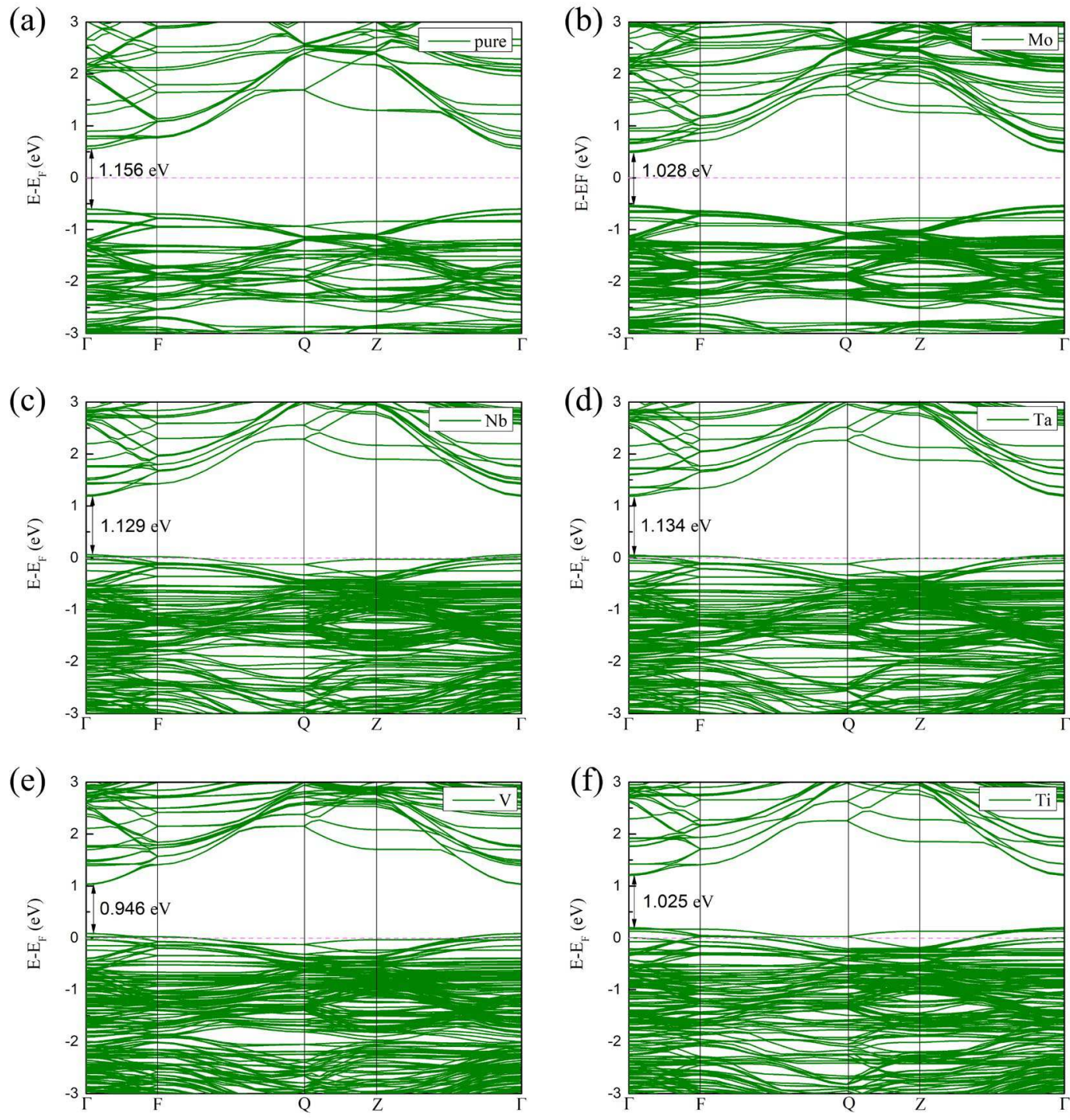

Fig. 4. Band structures of bleached pure $\mathrm{WO}_{3}$ and $\mathrm{M}_{0.125} \mathrm{WO}_{3}(\mathrm{M}=\mathrm{Mo}, \mathrm{Nb}, \mathrm{Ta}, \mathrm{V}, \mathrm{Ti})$.

After $\mathrm{Li}^{+}$are inserted, in colored state, $\mathrm{Li}$ s-electrons occupy the conduction energy levels $E_{\mathrm{c}}$ position with bonds between $\mathrm{O}$ atoms (Fig. 5 (a)). Compared with bleached state (Fig. 4 (a)), the structure of the band does not change much while several bands move below $E_{\mathrm{Fermi}}$. Both in the pure system and $\mathrm{Mo} / \mathrm{Nb} / \mathrm{Ta} / \mathrm{V}$ doping system, $E_{\mathrm{Fermi}}$ is elevated into conduction band with a similar band structure. However, in Ti doping system, (Fig. 5 (f)) its band structure corresponds to the Boltzmann distribution with an $E_{\text {Fermi }}$ in the middle of band gap. The $E_{\mathrm{g}}$ of the pure system is $1.064 \mathrm{eV}$ and the one of Mo, $\mathrm{Nb}, \mathrm{Ta}, \mathrm{V}$ and Ti doping system is $1.313 \mathrm{eV}, 1.475 \mathrm{eV}, 1.455 \mathrm{eV}, 1.315 \mathrm{eV}$ and $1.559 \mathrm{eV}$, respectively (Fig. 5 (a)-(e)). Except for the Ti system, in colored state, with a 
high doping, $\mathrm{Mo} / \mathrm{Nb} / \mathrm{Ta} / \mathrm{V}_{0.125} \mathrm{~W}_{0.875} \mathrm{O}_{3}$ are all in degeneration state which accord with the Fermi-Dirac distribution. As a result, there exist more electrons in the conduction band.

(a)

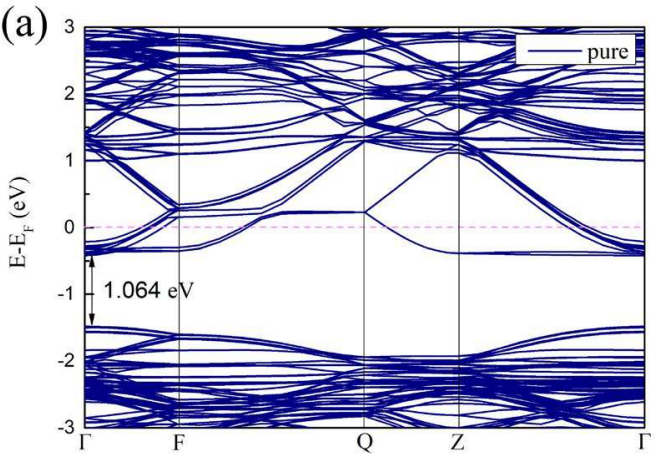

(c)

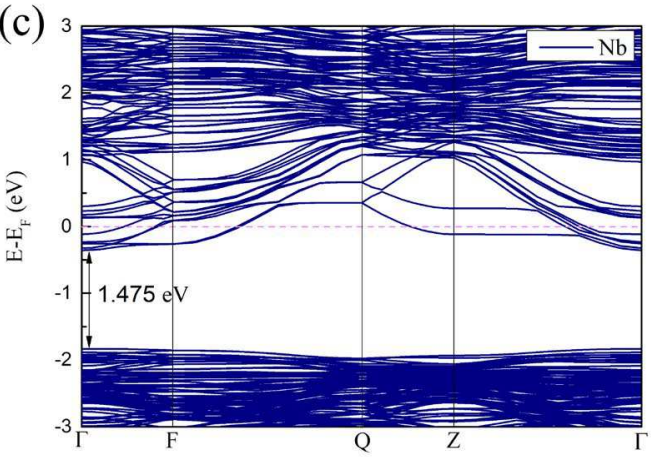

(e)

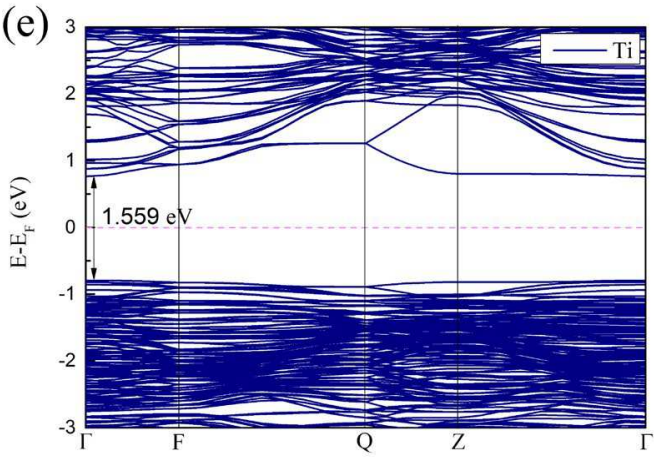

(b)

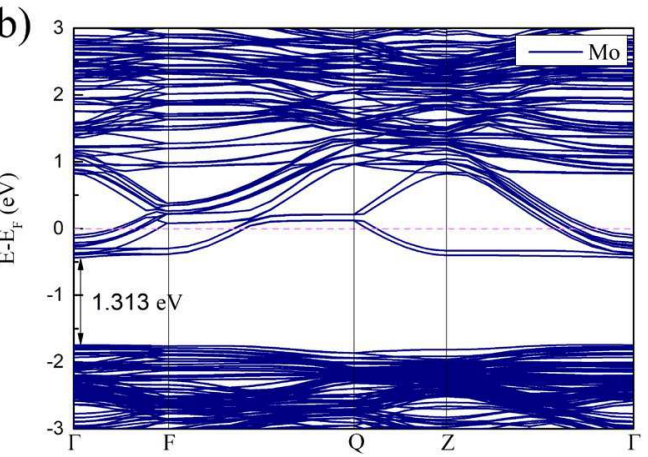

(d)
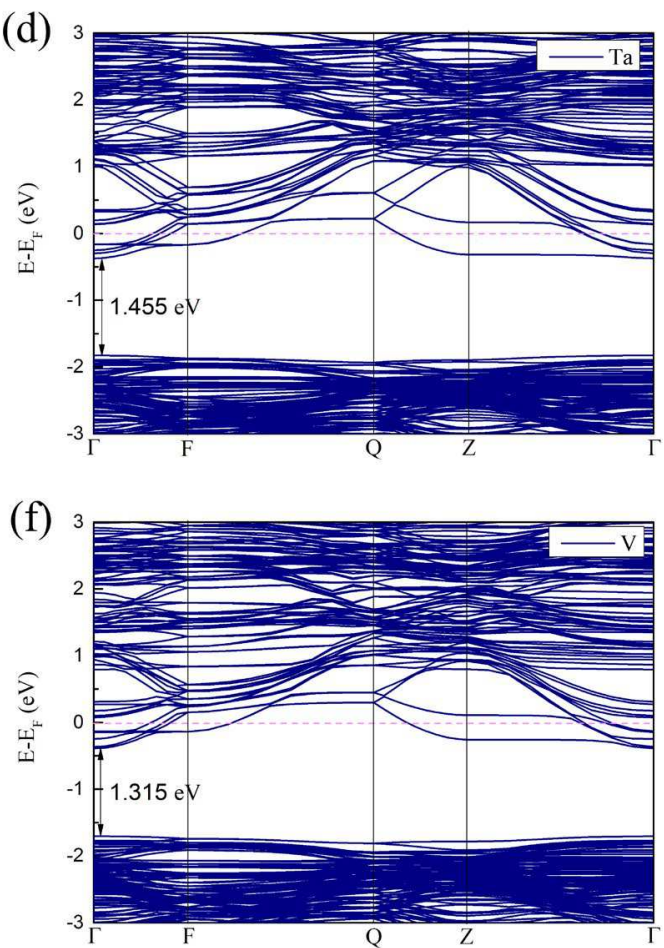

Fig. 5. Band structures of colored state pure $\mathrm{WO}_{3}$ and $\mathrm{M}_{0.125} \mathrm{WO}_{3}(\mathrm{M}=\mathrm{Mo}, \mathrm{Nb}, \mathrm{Ta}, \mathrm{V}, \mathrm{Ti})$.

\subsection{Optical properties of $M_{x} \mathrm{WO}_{3}$ in bleached states and colored states}

The physical properties and change tendency of $M_{0.125} \mathrm{~W}_{0.875} \mathrm{O}_{3}(M=\mathrm{Mo}, \mathrm{Nb}, \mathrm{Ta}$, V, Ti) are demonstrated and compared by radar pictures and table (Fig. 6 and Table 2), in which absorption and reflectivity are all integral areas in two infrared region and 
visible light region. For the details of optical properties of each doping sysyem, please see the supplementary materials. In bleached state, $\mathrm{Mo}_{0.125} \mathrm{~W}_{0.875} \mathrm{O}_{3}$ has a low transmissivity in the infrared region as pure $\mathrm{WO}_{3}$; it has a slightly higher absorption of visible light than pure $\mathrm{WO}_{3}$. However, in colored state, $\mathrm{Mo}_{0.125} \mathrm{~W}_{0.875} \mathrm{O}_{3}$ has much higher absorption and reflectivity in the infrared region than pure $\mathrm{WO}_{3}$, which indicated that $\mathrm{Mo}_{0.125} \mathrm{~W}_{0.875} \mathrm{O}_{3}$ appears to have a more effective modulation of infrared light than pure $\mathrm{WO}_{3}$. When it involves the visible light region, compared with pure $\mathrm{WO}_{3}$, in colored state, the absorption of $\mathrm{Mo}_{0.125} \mathrm{~W}_{0.875} \mathrm{O}_{3}$ is $31.4 \%$ higher than the one of pure $\mathrm{WO}_{3}$; the reflectivity of $\mathrm{Mo}_{0.125} \mathrm{~W}_{0.875} \mathrm{O}_{3}$ is $5.3 \%$ lower than the one of pure $\mathrm{WO}_{3}$. Thus, the $\mathrm{Mo}_{0.125} \mathrm{~W}_{0.875} \mathrm{O}_{3}$ has a more efficient electrochromic property than pure $\mathrm{WO}_{3}$. As it is concluded before, $\mathrm{Nb} / \mathrm{Ta} / \mathrm{V}_{0.125} \mathrm{~W}_{0.875} \mathrm{O}_{3}$ have the same tendency in the spectrum. In bleached state, $\mathrm{Nb} / \mathrm{Ta} / \mathrm{V}_{0.125} \mathrm{~W}_{0.875} \mathrm{O}_{3}$ have a higher absorption and reflectivity in infrared light region $\left(\alpha_{i}, R_{i}\right)$ and lower absorption and reflectivity in visible light region $\left(\alpha_{\mathrm{v}}, \mathrm{R}_{\mathrm{v}}\right)$ than pure $\mathrm{WO}_{3}$. In colored state, $\mathrm{Nb} / \mathrm{Ta} / \mathrm{V}_{0.125} \mathrm{~W}_{0.875} \mathrm{O}_{3}$ have high absorption and reflectivity in infrared light region $\left(\alpha_{\mathrm{i}}, \mathrm{R}_{\mathrm{i}}\right)$, which suggests that $\mathrm{Nb}, \mathrm{Ta}, \mathrm{V}$ doping makes $\mathrm{WO}_{3}$ has high transmissivity of infrared region both in bleached and colored states. Nevertheless, $\mathrm{Nb}, \mathrm{Ta}, \mathrm{V}$ doped $\mathrm{WO}_{3}$ still has a lower transmissivity of visible light in colored state compared with bleached state. Thus, $\mathrm{Nb}$, Ta, $\mathrm{V}$ doping make $\mathrm{WO}_{3}$ an electrochromic material with only visible light modulation. $\operatorname{Ti}_{0.125} \mathrm{~W}_{0.875} \mathrm{O}_{3}$ has a high transmissivity of visible light and low transmissivity of infrared light in bleached state; in colored state, the transmissivity of infrared light slumped nearly to 0 . This phenomenon unveils a utilization of $\mathrm{Ti}_{0.125} \mathrm{~W}_{0.875} \mathrm{O}_{3}$ in the smart window field. Our calculations are in agreement with experimental results. For example, it is experimented by $\mathrm{K}$. Gesheva et al. [21] that $\mathrm{WO}_{3}-\mathrm{MoO}_{3}$ material has a higher absorption and lower transmissivity of visible light in bleached state, which corresponds with the simulation result. Compared with experimented results from A. Rougier et al. [37] and D. Yang et al.[38], the experimental results also concluded that $\mathrm{Nb}, \mathrm{Ta}, \mathrm{V}$ doped $\mathrm{WO}_{3}$ possess a lighter color in bleached state than pure $\mathrm{WO}_{3}$ and deep color in colored state. In 
$\mathrm{Ti}_{0.125} \mathrm{~W}_{0.875} \mathrm{O}_{3}$, as it is experimented by $\mathrm{H}$. Shinguu et al. [39], the existence of Ti may reduce the transmissivity of visible light in bleached state, which accords with the simulation result in this work.

Table 2 Changing tendency of optical properties in different doping system ( $\uparrow:$ increase; $\downarrow$ :decrease; -:no remarkable change; $\alpha_{\mathrm{i}}$ : absorption of infrared light; $\mathrm{R}_{\mathrm{i}}$ : reflectivity of infrared light; $\mathrm{T}_{\mathrm{i}}$ : transmissivity of infrared light; $\alpha_{\mathrm{v}}$ : absorption of visible light; $\mathrm{R}_{\mathrm{v}}$ : reflectivity of visible light; $\mathrm{T}_{\mathrm{v}}$ : transmissivity of visible light).

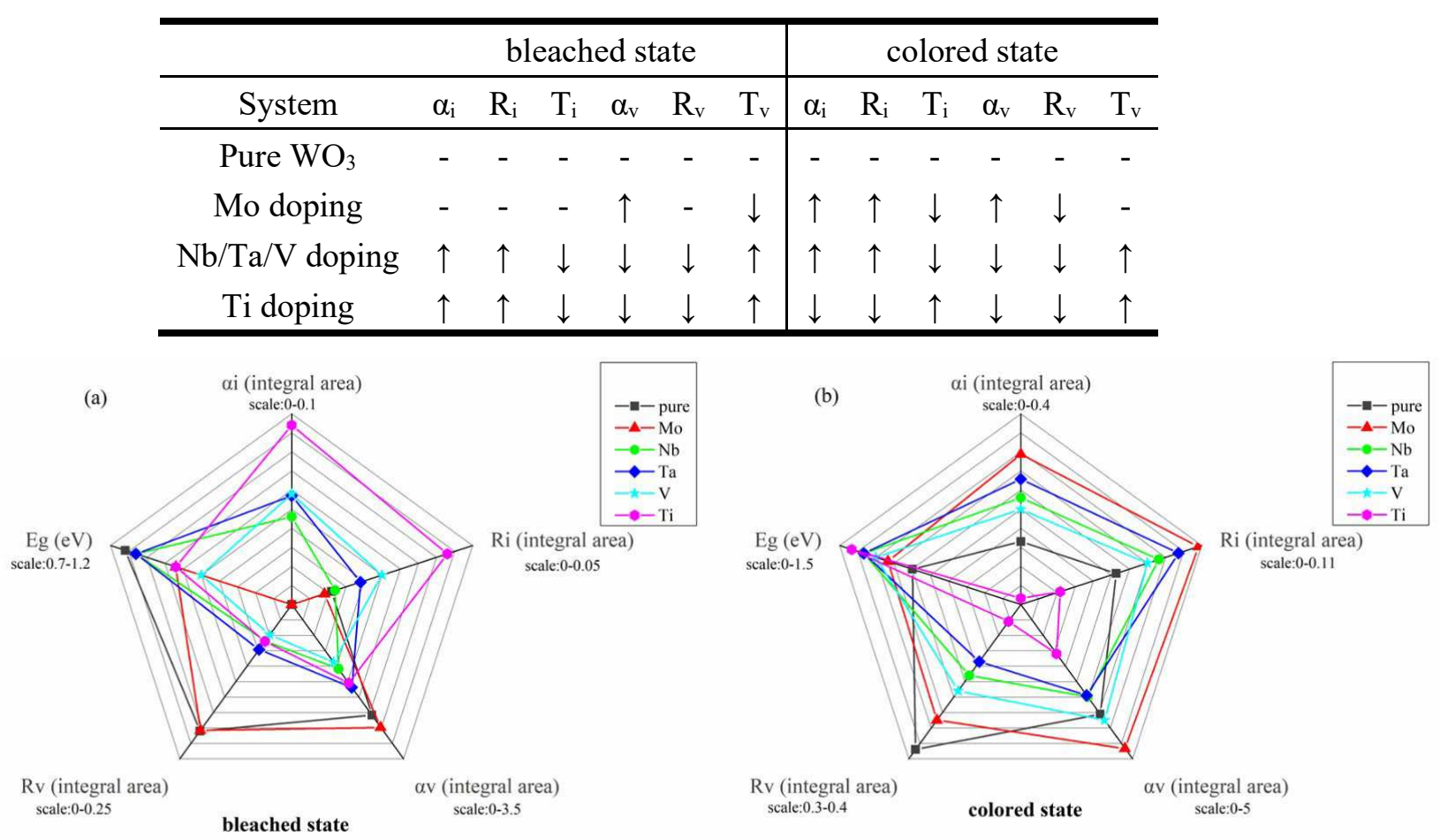

Fig. 6. Properties of $M_{0.125} \mathrm{~W}_{0.875} \mathrm{O}_{3}(M=\mathrm{Mo}, \mathrm{Nb}, \mathrm{Ta}, \mathrm{V}, \mathrm{Ti})$; Five kinds of properties are considered: absorption $\left(\alpha_{\mathrm{i}},\right)$ and reflectivity in the infrared region $\left(\alpha_{\mathrm{i}}, R_{\mathrm{i}}\right)$ and the visible region $\left(\alpha_{\mathrm{v}}, R_{\mathrm{v}}\right)$ and band gap $\left(E_{\mathrm{g}}\right)$. Optical properties are all presented by integral area.

\section{Conclusion}

In summary, optical properties of $\mathrm{Mo}, \mathrm{Nb}, \mathrm{Ta}, \mathrm{V}$, Ti doped $\mathrm{WO}_{3}$ are investigated through first-principles calculations. It is revealed that Mo doping can improve the coloration efficiency of $\mathrm{WO}_{3}$, especially in the infrared region. Moreover, we predict that $\mathrm{Nb}$, Ta, $\mathrm{V}$, Ti doping may greatly alter optical properties of $\mathrm{WO}_{3}$ both in bleached 
state and colored state. Results suggest that $M_{0.125} \mathrm{~W}_{0.875} \mathrm{O}_{3}(M=\mathrm{Nb}$, Ta, V) has low transmissivity of infrared light in both bleached and colored states but the transmissivity of visible light is high in bleached state and low in colored state, which indicates that this kind of electrochromic material only has modulation in the visible light region. $\mathrm{Ti}$ doping makes $\mathrm{WO}_{3}$ always has a high transmissivity of visible light during the coloration process, yet in the infrared region, it is transparent when the $\mathrm{Ti}_{0.125} \mathrm{~W}_{0.875} \mathrm{O}_{3}$ is colored and it is opaque when it is bleached. With the modulation of visible light, $M_{0.125} \mathrm{~W}_{0.875} \mathrm{O}_{3}(M=\mathrm{Nb}, \mathrm{Ta}, \mathrm{V})$ can be used as smart window in summer. On contrary, $\mathrm{Ti}_{0.125} \mathrm{~W}_{0.875} \mathrm{O}_{3}$ can be applied as the smart material of greenhouse.

\section{Acknowledgments}

The authors gratefully acknowledge the support from the National Natural Science Foundation of China (51972206 and 51873102), the Ministry of Science and Technology of China (2016YFB0303901-05), the Shanghai Municipal Science and Technology Commission (18JC1412800) and the Innovation Program of Shanghai Municipal Education Commission (No. 2019-01-07-00-09-E00020).

\section{References}

[1]. S.K. Deb, A novel electrophotographic system, Appl. Opt. 8 (S1) (1969) 192195. https://doi.org/10.1364/AO.8.S1.000192.

[2]. H. Zheng, J. Ou, M. S. Strano, R. B. Kaner, A. Mitchell, K. Kalantar-zadeh, Nanostructured tungsten oxide-properties, synthesis, and applications, Adv. Funct. Mater. 21 (12) (2011) 2175-2196. https://doi.org/10.1002/adfm.201002477.

[3]. C. Yang, J. Chen, X. Zeng, D. Cheng, D. Cao, Design of the alkali-metaldoped $\mathrm{WO}_{3}$ as a near-infrared shielding material for smart window, Ind. Eng. Chem. Res. 53 (46) (2014) 17981-17988. http://doi.org/10.1021/ie503284x.

[4]. S. Cong, F. Geng, Z. Zhao, Tungsten oxide materials for optoelectronic $\begin{array}{lllllll}\text { applications, } & \text { Adv. } & \text { Mater. } & 28 & \text { (47, } & \text { SI) } & \text { (2016) }\end{array}$ 
https://doi.org/10.1002/adma.201601109.

[5]. G.A. de Wijs, R.A. de Groot, Amorphous $\mathrm{WO}_{3}$ : a first-principles approach, Electrochim. Acta. 46 (13-14) (2001) 1989-1993. https://doi.org/10.1016/S00134686(01)00377-2.

[6]. G.A. Niklasson, C.G. Granqvist, Electrochromics for smart windows: thin films of tungsten oxide and nickel oxide, and devices based on these, J. Mater. Chem. 17 (2) (2007) 127-156. https://doi.org/10.1039/B612174H.

[7]. B.W. Faughnan, R.S. Crandall, M.A. Lampert, Model for the bleaching of $\mathrm{WO}_{3}$ electrochromic films by an electric field, Appl. Phys. Lett. 27 (5) (1975) 275-277. https://doi.org/10.1063/1.88464.

[8]. R.S. Crandall and B.W. Faughnan, Measurement of the diffusion coefficient of electrons in $\mathrm{WO}_{3}$ films, Appl. Phys. Lett. 26 (3) (1975.) 120-121. https://doi.org/10.1063/1.88087.

[9]. S.K. Deb, Opportunities and challenges in science and technology of $\mathrm{WO}_{3}$ for electrochromic and related applications, Sol. Energ. Mat. Sol. C. 92 (2) (2008) 245-258. https://doi.org/10.1016/j.solmat.2007.01.026.

[10]. Z. Huang, J. Song, L. Pan, X. Zhang, L. Wang, J. Zou, Tungsten oxides for photocatalysis, electrochemistry, and phototherapy, Adv. Mater. 27 (36) (2015) 53095327. https://doi.org/10.1002/adma.201501217.

[11]. C.G. Granqvist, Handbook of inorganic electrochromic materials. 1995: Elsevier Science.

[12]. L. Berggren, Optical absorption and durability of sputtered amorphous tungsten oxide films, Solid. State. Ionics. 165 (1-4) (2003) 51-58. https://doi.org/10.1016/j.ssi.2003.08.016.

[13]. W. Wang, H. Peelaers, J. Shen, C.G. Van de Walle, Carrier-induced absorption as a mechanism for electrochromism in tungsten trioxide, MRS. Commun. 8 (03) (2018) 926-931. https://doi.org/10.1557/mrc.2018.115.

[14]. H. Lin, F. Zhou, C. Liu, V. Ozoliņ̌s, Non-Grotthuss proton diffusion 
mechanism in tungsten oxide dihydrate from first-principles calculations, J. Mater. Chem. A. 2 (31) (2014) 12280. https://doi.org/10.1039/C4TA02465F.

[15]. G.A. de Wijs, R.A. de Groot, Lithium trapping by excess oxygen in $\mathrm{WO}_{3}$ : A first-principles study, Phys. Rev. B. $62 \quad$ (3) (2000) 1508-1511. https://doi.org/10.1103/PhysRevB.62.1508.

[16]. Y. Xue, Y. Zhang, P. Zhang, Theory of the color change of $\mathrm{Na}_{\mathrm{x}} \mathrm{WO}_{3}$ as a function of Na-charge doping, Phys. Rev. B. $79 \quad$ (2009) 20511320. https://doi.org/10.1103/PhysRevB.79.205113.

[17]. B.W. Faughnan, R.S. Crandall, Optical properties of mixed-oxide $\mathrm{WO}_{3} / \mathrm{MoO}_{3}$ electrochromic films, Appl. Phys. Lett. 31 (12) (1977) 834-836. https://doi.org/10.1063/1.89566.

[18]. R.S. Crandall, B.W. Faughnan, Dynamics of coloration of amorphous electrochromic films of $\mathrm{WO}_{3}$ at low voltages, Appl. Phys. Lett. 28 (2) (1976) 95-97. https://doi.org/10.1063/1.88653.

[19]. K. Wang, P. Zeng, J. Zhai, Q. Liu, Electrochromic films with a stacked structure of $\mathrm{WO}_{3}$ nanosheets, Electrochem. Commun. $26 \quad$ (2013) 5-9. https://doi.org/10.1016/j.elecom.2012.09.037.

[20]. Z. Jiao, X. Sun, J. Wang, L. Ke, H. V. Demir, Hydrothermally grown nanostructured $\mathrm{WO}_{3}$ films and their electrochromic characteristics, J. Phys. D: Appl. Phys. 43 (28) (2010) 285501. http://doi.org/10.1088/0022-3727/43/28/285501.

[21]. K. Gesheva, A. Szekeres, T. Ivanova, Optical properties of chemical vapor deposited thin films of molybdenum and tungsten based metal oxides, Sol. Energ. Mat. Sol. C. 76 (4) (2003) 563-576. https://doi.org/10.1016/S0927-0248(02)00267-2.

[22]. K. Park, Electrochromic properties of $\mathrm{Au}-\mathrm{WO}_{3}$ nanocomposite thin-film electrode, Electrochim. Acta. $50 \quad$ (24) (2005) 4690-4693. https://doi.org/10.1016/j.electacta.2005.03.001.

[23]. A.E. Aliev, H.W. Shin, Nanostructured materials for electrochromic devices, Solid. State. Ionics. 154-155 (2002) 425-431. https://doi.org/10.1016/S0167- 
2738(02)00479-4.

[24]. Y. Nah, A. Ghicov, D. Kim, S. Berger, P. Schmuki, $\mathrm{TiO}_{2}-\mathrm{WO}_{3}$ Composite nanotubes by alloy anodization: growth and enhanced electrochromic properties, J. Am. Chem. Soc. 130 (48) (2008) 16154-16155. https://doi.org/10.1021/ja807106y. [25]. P.E. Blöchl, Projector augmented-wave method, Phys. Rev. B. 50 (1994). 17953-17979. https://doi.org/10.1103/PhysRevB.50.17953.

[26]. J.P. Perdew, K. Burke and M. Ernzerhof, Generalized gradient approximation made simple, Phys Rev Lett. 77 (18) (1996) 3865-3868. https://doi.org/10.1103/PhysRevLett.77.3865.

[27]. G. Kresse, J. Hafner, Ab initio molecular dynamics for liquid metals, Phys Rev. B. Condens. Matter. 47 (1) (1993) 558-561. https://doi.org/10.1103/PhysRevB.47.558. [28]. B. Wang, W. Zhang, K. Yang, T. Liao, F. Li, Y. Cui, Y. Gao, B. Liu, Metal dopants adjusted perovskite stannates: Conductivity and optical properties, Ceram. Int. 44 (13) (2018) 16051-16057. https://doi.org/10.1016/j.ceramint.2018.06.046. [29]. Y. Liu, Y. Zhou, D. Jia, J. Zhao, B. Wang, Y. Cui, Q. Li, B. Liu, Composition dependent intrinsic defect structures in $\mathrm{ASnO} 3(\mathrm{~A}=\mathrm{Ca}, \mathrm{Sr}, \mathrm{Ba})$, J. Mater. Sci. Technol. 42 (2020) 212-219. https://doi.org/10.1016/j.jmst.2019.10.015. [30]. Y. Cui, K. Yang, B. Wang,J Feng, B. Liu, G. Yang, Y. Gao, First-principles study of phase-transition temperature and optical properties of alkaline earth metal (Be, Mg, Ca, Sr or Ba)-doped VO2. Ceramics International, 44 (17) (2018) 2081420820. https://doi.org/10.1016/j.ceramint.2018.08.084.

[31]. A. Antonaia, M.L. Addonizio, C. Minarini, T. Polichetti, M.Vittori-Antisari, Improvement in electrochromic response for an amorphous/crystalline $\mathrm{WO}_{3}$ double layer, Electrochim. Acta. 46 (13-14) (2001) 2221-2227. https://doi.org/10.1016/S00134686(01)00405-4.

[32]. J. Grannec, A. Yacoubi, J. Ravez, P. Hagenmuller, New oxyfluorides containing indium with potential ferroelastic properties, J. Solid. State. Chem. 75 (2) (1988) 263-269. https://doi.org/10.1016/0022-4596(88)90165-X. 
[33]. Z. Wang, Y. He, M. Gu, Y. Du, S.X. Mao, C. Wang, Electron transfer governed crystal transformation of tungsten trioxide upon Li ions Intercalation, ACS. Appl Mater Inter. 8 (37) (2016) 24567-24572.

https://doi.org/10.1021/acsami.6b06581.

[34]. H.M. Le, N.H. Vu, B. Phan, Migrations of oxygen vacancy in tungsten oxide $\left(\mathrm{WO}_{3}\right)$ : a density functional theory study, Comp. Mater. Sci. 90 (2014) 171-176. https://doi.org/10.1016/j.commatsci.2014.04.018.

[35]. C. Lambert-Mauriat, V. Oison, Density-functional study of oxygen vacancies in monoclinic tungsten oxide, J. Phys-Condens. Mat. 18 (31) (2006) 7361-7371. http://doi.org/10.1088/0953-8984/18/31/028.

[36]. F.G.A. Fernández, F.G. Camacho, J.A.S. Pérez, J.M.F. Sevilla, E.M. Grima, A model for light distribution and average solar irradiance inside outdoor tubular photobioreactors for the microalgal mass culture, Biotechnol. Bioeng. 55 (5) (1997) 701-714. https://doi.org/10.1002/(SICI)1097-0290(19970905)55:5\%3C701::AIDBIT1\%3E3.0.CO;2-F.

[37]. A. Rougier, A. Blyr, J. Garcia, Q. Zhang, S.A. Impey, Electrochromic W-M$\mathrm{O}(\mathrm{M}=\mathrm{V}, \mathrm{Nb})$ sol-gel thin films: a way to neutral colour, Sol. Energ. Mat. Sol. C. 71 (3) (2002) 343-357. https://doi.org/10.1016/S0927-0248(01)00092-7.

[38]. D. Yang, L. Xue, Structures and electrochromic properties of $\mathrm{Ta}_{0.1} \mathrm{~W}_{0.9} \mathrm{O}_{\mathrm{x}}$ thin films deposited by pulsed laser ablation, Thin. Solid. Films. 469-470 (2004) 54-58. https://doi.org/10.1016/j.tsf.2004.06.187.

[39]. H. Shinguu, M.M.H. Bhuiyan, T. Ikegami, K. Ebihara, Preparation of $\mathrm{TiO}_{2} / \mathrm{WO}_{3}$ multilayer thin film by PLD method and its catalytic response to visible light, Thin. Solid. Films. 506-507 (2006) 111-114. https://doi.org/10.1016/j.tsf.2005.08.312. 

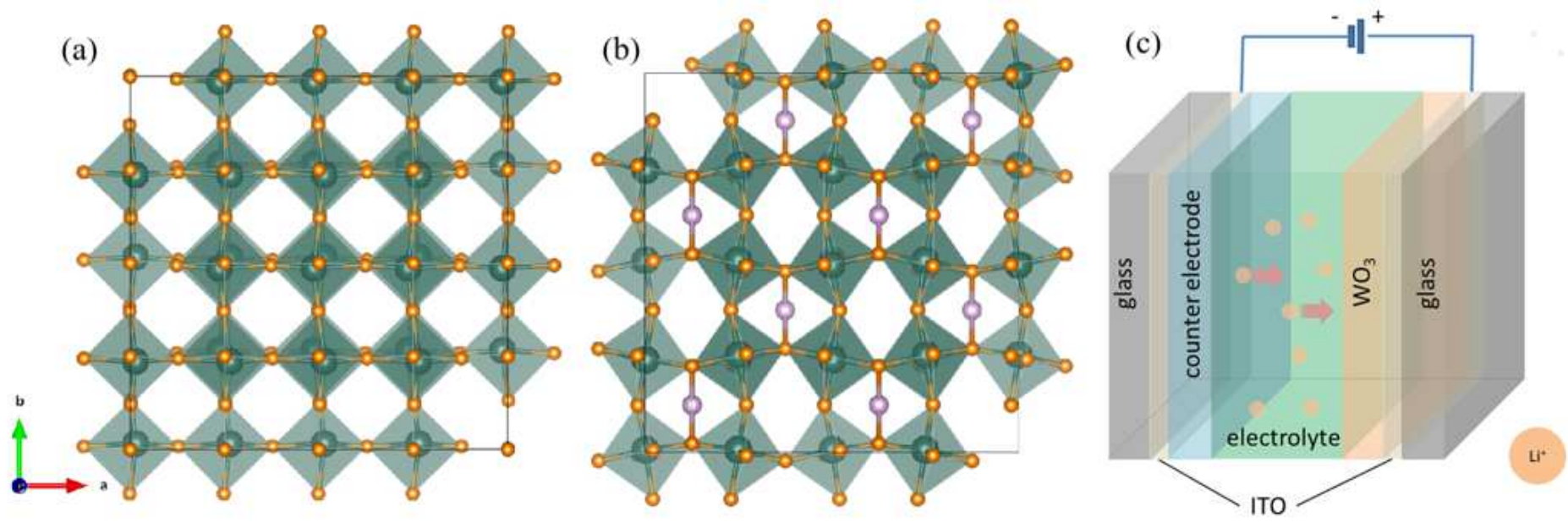

Figure 1

The structure of (a) pure $\mathrm{y}$-WO3; (b) LixWO3; green octahedrons: WO6; orange atoms: 0 atoms; pink atoms: Li atoms; green atoms: W (c) the sandwich appliance of electrochromic materials octahedrons.

(a)

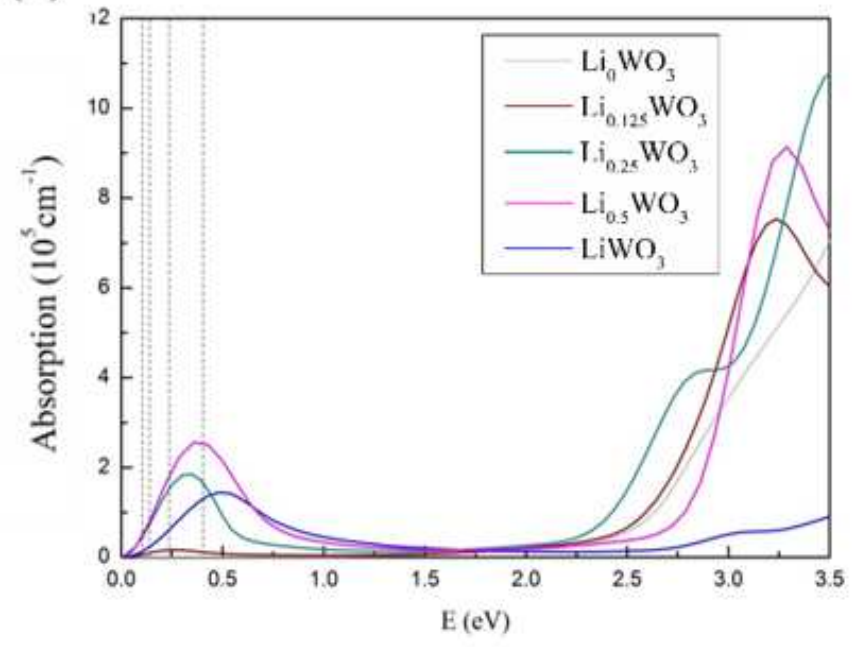

(b)

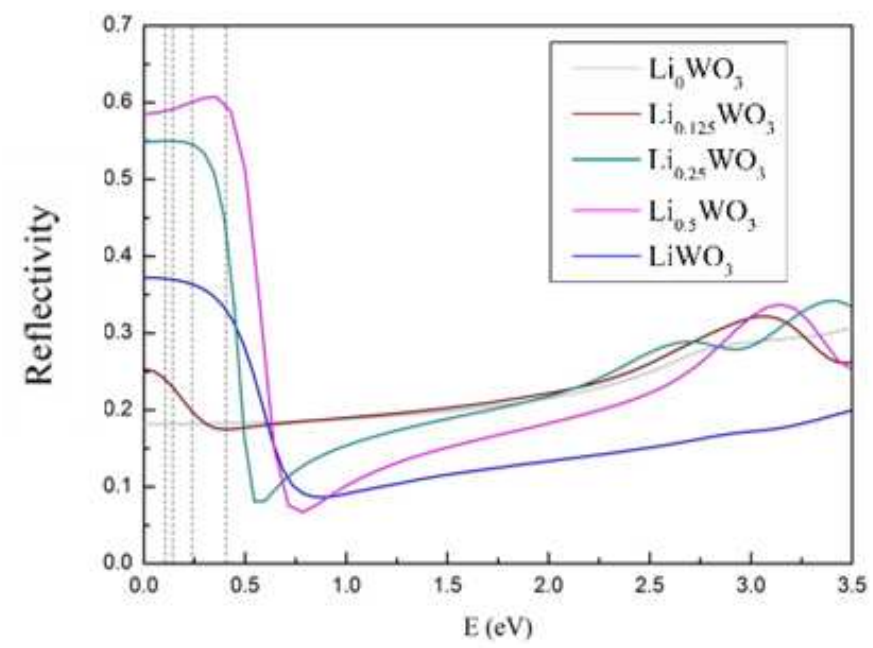

\section{Figure 2}

Optical properties of colored WO3 in NIR and visible light range (a) absorption (b) reflectivity; dash lines highlight two infrared atmospheric windows. 

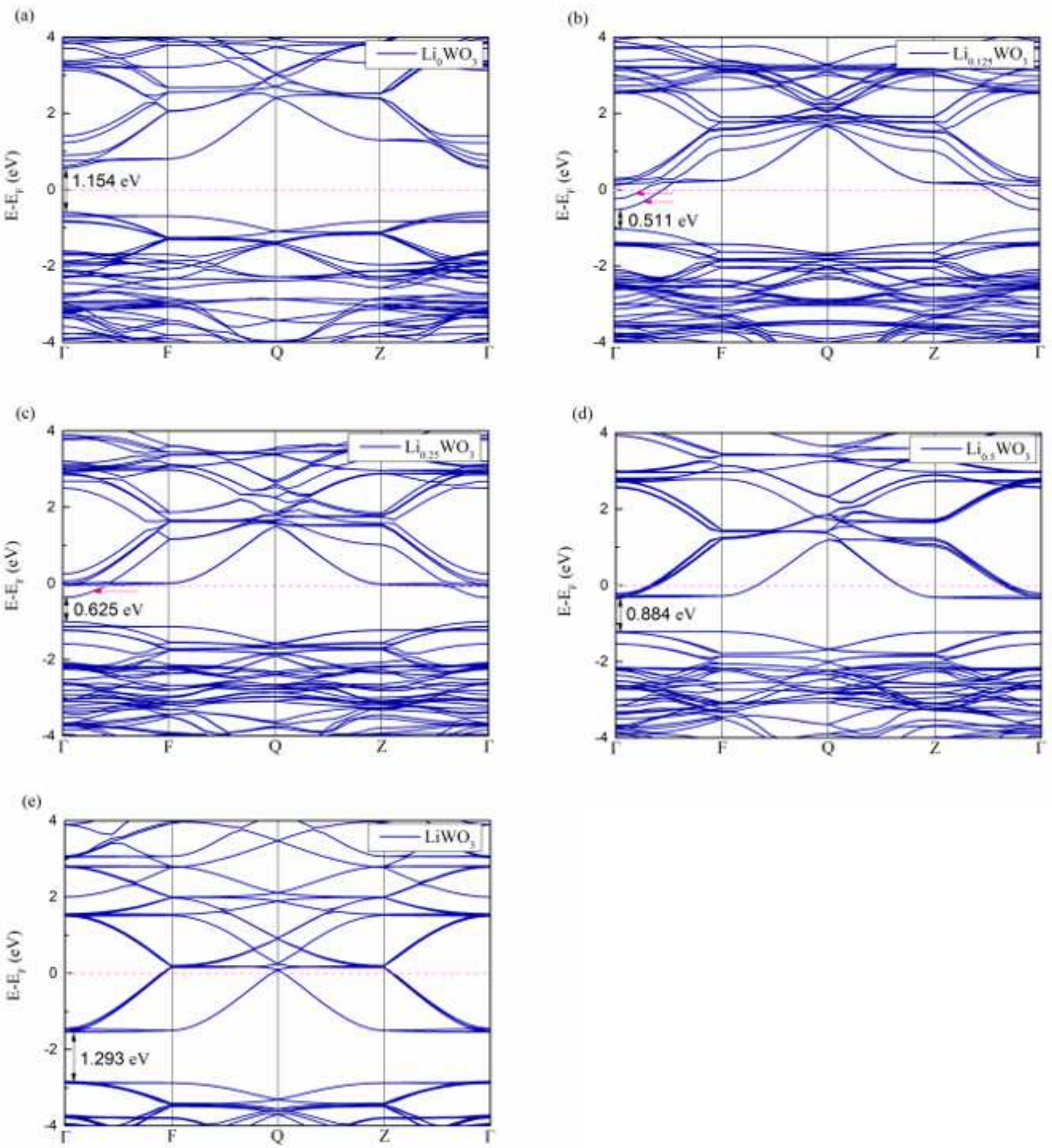

\section{Figure 3}

Band structures of LixWO3 systems ( $x=0,0.125,0.25,0.5,1)$. 
(a)

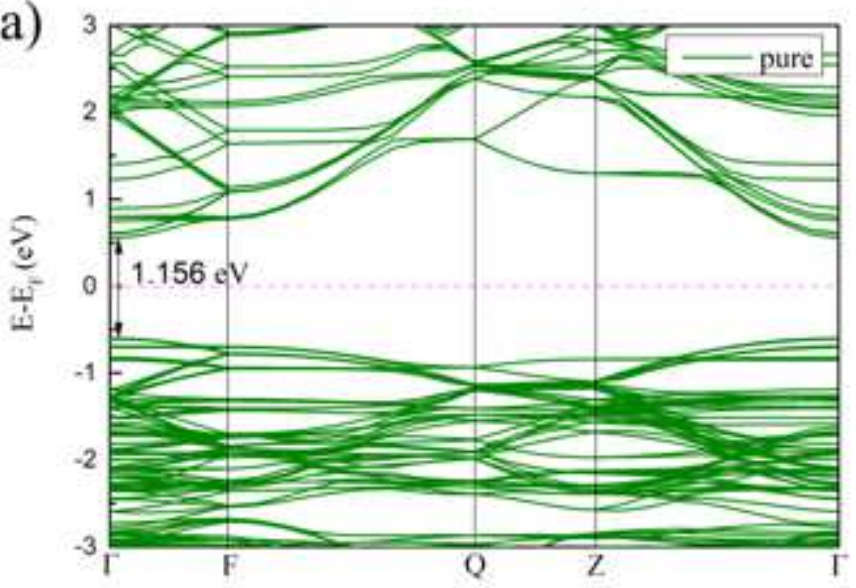

(c)

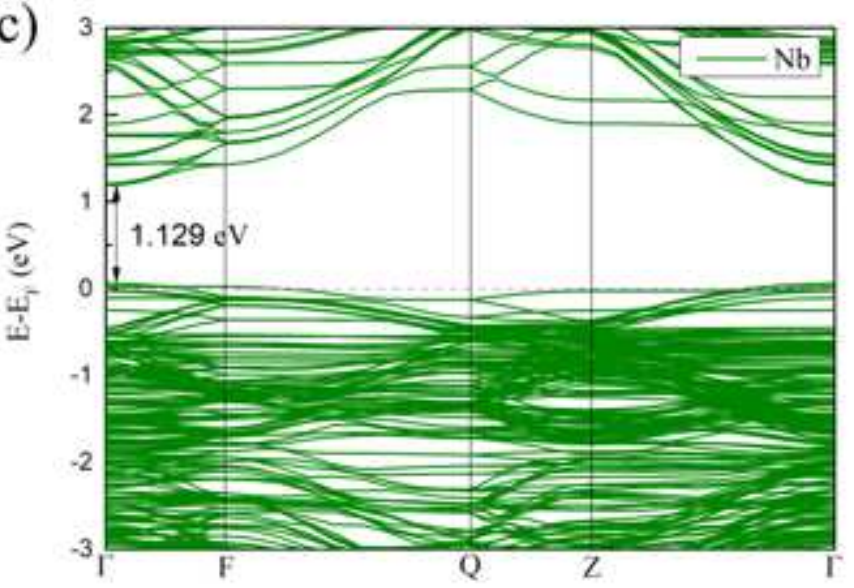

(e)

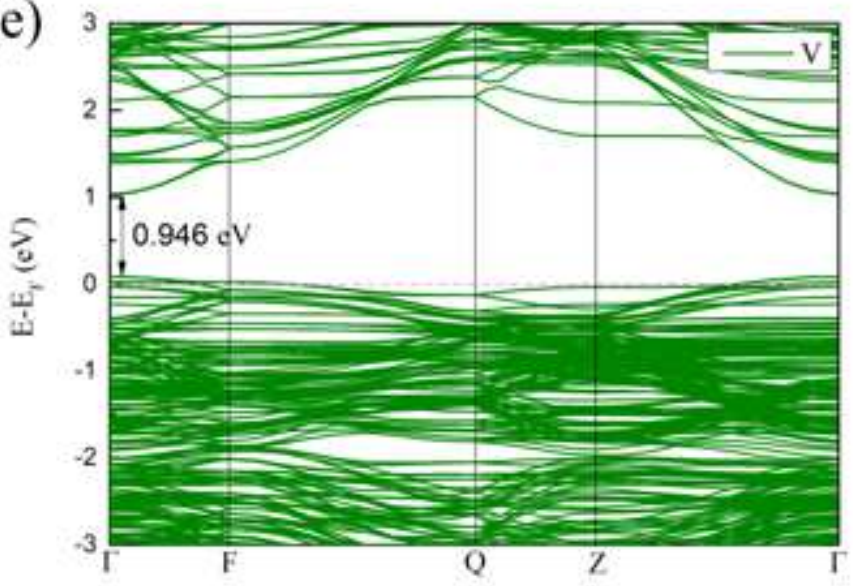

(b)

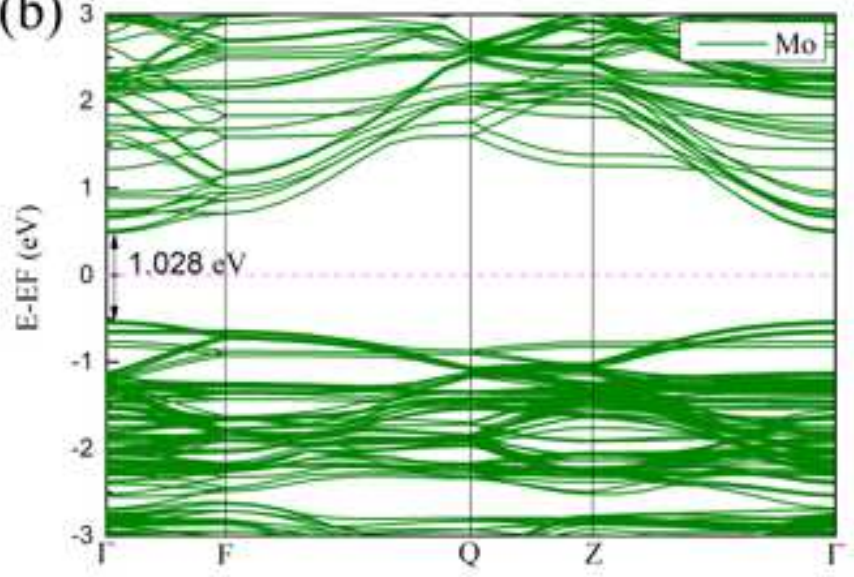

(d)
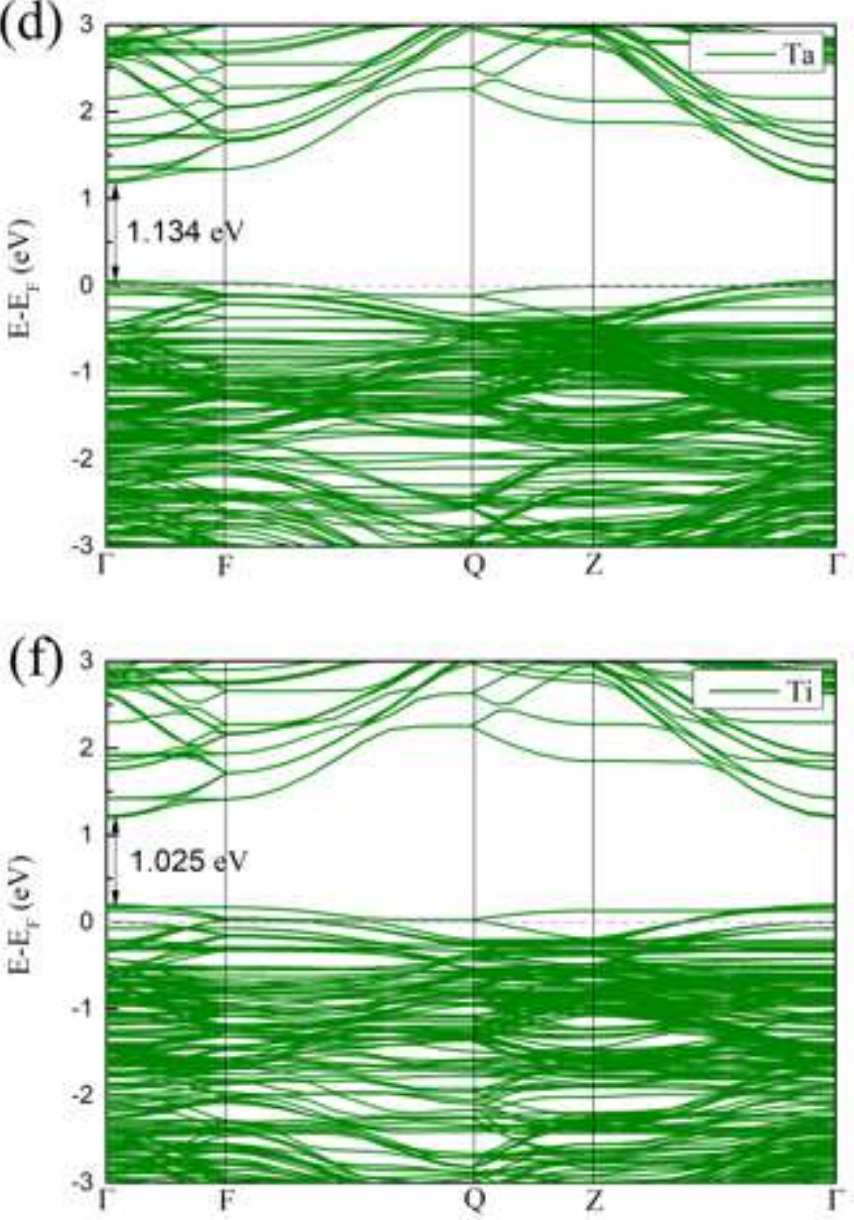

\section{Figure 4}

Band structures of bleached pure WO3 and M0.125WO3 (M=Mo, Nb, Ta, V, Ti). 

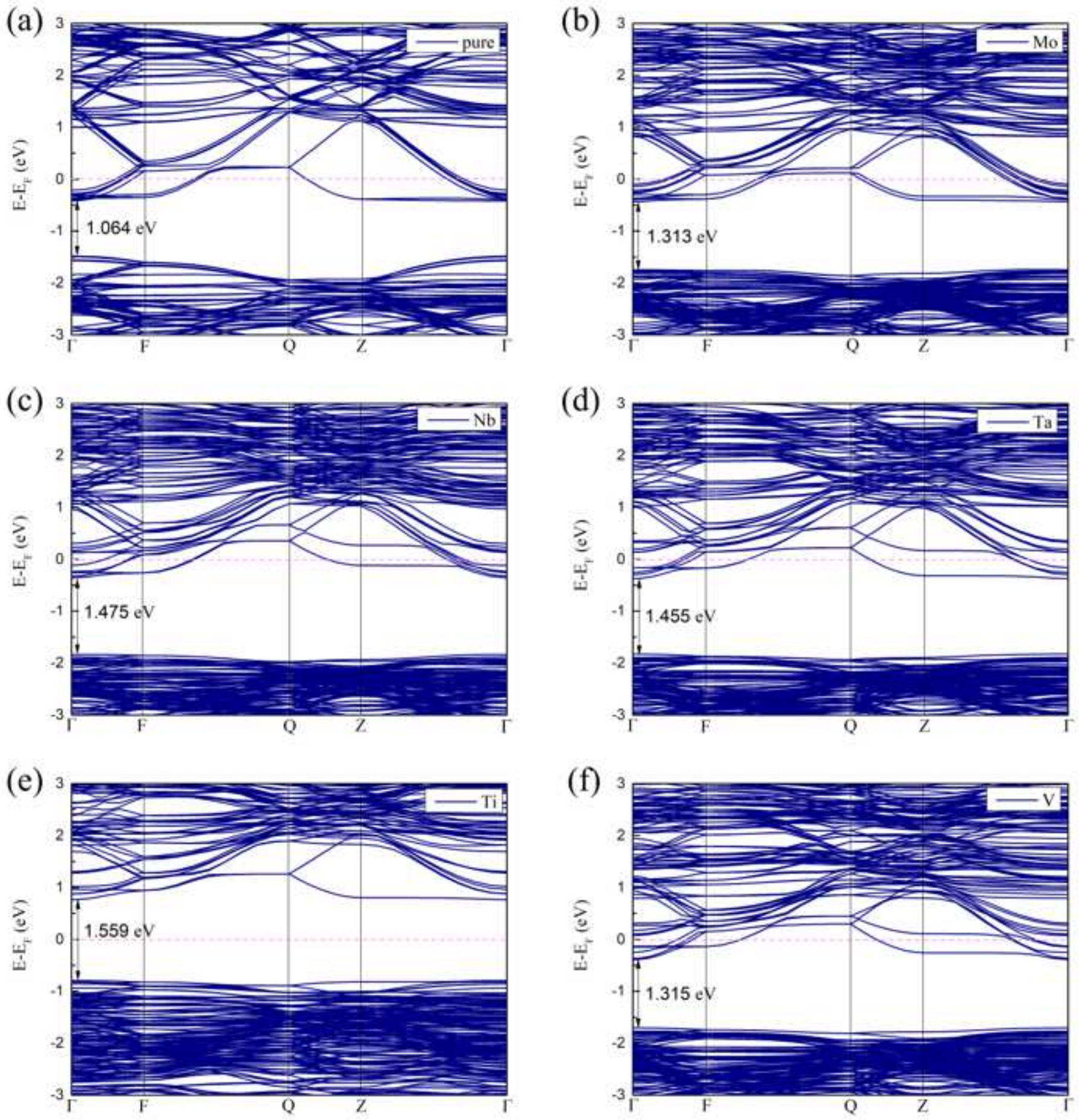

Figure 5

Band structures of colored state pure WO3 and M0.125WO3 (M=Mo, Nb, Ta, V, Ti). 


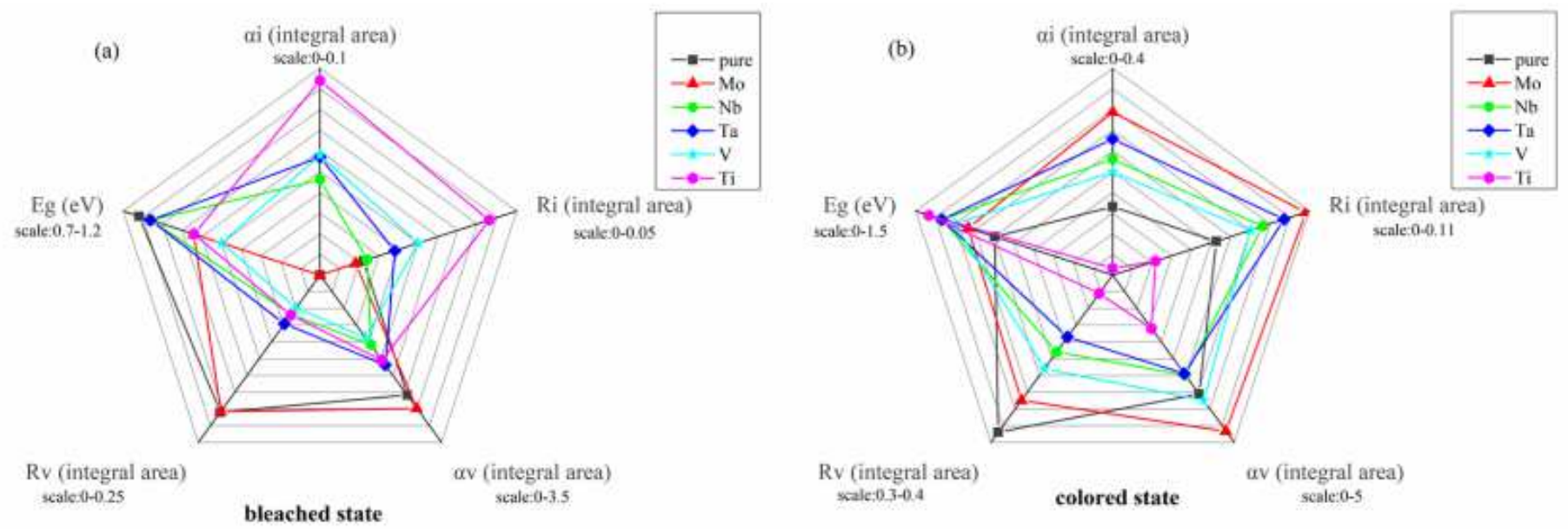

Figure 6

Properties of M0.125W0.87503 ( $\mathrm{M}=\mathrm{Mo}, \mathrm{Nb}, \mathrm{Ta}, \mathrm{V}, \mathrm{Ti})$; Five kinds of properties are considered: absorption (ai,) and reflectivity in the infrared region (ai, Ri) and the visible region (av, Rv) and band gap (Eg). Optical properties are all presented by integral area.

\section{Supplementary Files}

This is a list of supplementary files associated with this preprint. Click to download.

- Supplementarymaterials.docx

- Supplementarymaterials.docx 